Journal of Contemporary Educational Research

Research Article

\title{
Research on Curriculum Attainment Evaluation System Based on Learning Outcomes in Universities
}

Zhentong $\mathrm{Fu}$

Daqing Normal University, Daqing 163712, Heilongjiang Province, China

Funding: Key project of Education and Teaching Reform of Daqing Normal University research on Curriculum Development Integrity Evaluation System of Reverse Design Teaching (No. JY1904).

\begin{abstract}
With the continuous development and improvement of educational concepts, the effectiveness of learning outcomes and the achievement of curriculum has become an important way to change the present situation of teaching. This paper explores the construction of the curriculum achievability evaluation system based on learning outcomes from three aspects, namely, phased learning outcomes, graduation requirements, graduation design requirements and employability requirements, which are closely related to learning outcomes, in order to contribute to the promotion of education reform and the improvement of teaching effectiveness.
\end{abstract}

Key words: Learning outcomes; Curriculum achievement; Evaluation system

Publication date: September, 2020

Publication online: 30 September, 2020

*Corresponding author: Zhentong Fu, Fuzhentong@126.com

For a long time, education has always been teachercentered and dominated. Although it is conducive to the systematic teaching and dissemination of knowledge, it has left deep worries in terms of the acceptability of students and the attainment of courses. With the development of times and the progress of educational concept, this educational phenomenon has been changed gradually, the direction of student-centered and studentcentered teaching has been continuously changed, and the new educational achievements have been obtained. Accordingly, a series of new education methods such as flipped classroom emerged. As a result, the evaluation method of educational effectiveness has also ushered in the opportunity of reform. This paper studies the construction of a curriculum attainment evaluation system for learning outcomes.

\section{The background and significance of the construction of the curriculum attainment evaluation system based on learning outcomes}

At present, domestic colleges and universities still take the examination as the main basis for the assessment of students' academic performance, and also take the examination results as the main standard for the evaluation of awards and excellence. Therefore, there is a situation in colleges and universities where academic performance and "priority" go hand in hand, that is, the score becomes the passport with absolute advantage. As long as the score is high, everything is guaranteed and you can get the first place in almost all aspects. It can be said that test scores become a concentrated manifestation of students' learning results on the one hand, and become the weights to obtain other benefits on the other hand. So, it can be seen that its disadvantages are more serious. On the one hand, exam scores cannot fully reflect students' academic level, which can only reflect students' memory ability and their test-taking ability from the side. They cannot truly reflect the improvement of students' comprehensive ability caused by their studies, nor can they reflect students' knowledge application ability. And because the examination is carried out in the form of examination paper, even more the length of the examination paper 
is limited that causes the one-sidedness of knowledge examination. On the other hand, depending on the exam results only, students will be more depressed to the pursuit of real ability and learning, and forcing students into the chase of scores. In addition, due to the connection between test scores and other interests such as awards and appraises, students' pursuit of scores is deepened, and their awareness of comprehensively improving their abilities and qualities through study is weakened, which deviates from the original intention of university education.

Course based on the learning outcomes of integrity evaluation system, pay attention to students' understanding of knowledge and application ability, pay attention to the transformation from knowledge to ability, from learning to the transformation of the application, from creative thinking to the transformation of the innovative practice, pay attention to the achievement of curriculum from the perspective of learning results, from the construction of evaluation system to replace the single evaluation standard of the examination results, and through the scientific evaluation system construction, expand the knowledge of practical evaluation, drive students to pursue allround development, promoting the comprehensive ability and the comprehensive qualities of students, so as to improve the level of education and teaching efficiency, and make the knowledge has taste, It also makes knowledge effective.

\section{The construction of curriculum attainment evaluation system based on learning outcomes}

From the perspective of learning outcomes, the curriculum can be showed in three aspects. The first is the phased learning outcome along with the course progress, which is an important aspect that can directly show the students' learning ability and the ability to grasp and apply knowledge. The second is the graduation design and graduation requirements that embody the learning achievement and show the achievement through the comprehensive ability of students. The third is the employability. In the employment process, from the interview to the fixed position and the later working life, it can be said that it is the ultimate examination of students' learning results and also the extension examination of students' academic ability. Therefore, the curriculum achievement evaluation system based on learning outcomes can also be constructed from the three aspects: stage learning outcomes, graduation design requirements and graduation requirements, and employability.

It is worth noting that, from the perspective of learning outcomes, the cultivation and improvement of learning ability is also an important project that constantly faces tests and investigations in employment. Therefore, the cultivation and evaluation of learning ability is more important than other learning outcomes, and should become an important item in the curriculum development evaluation system of learning outcomes.

\subsection{Build curriculum attainment evaluation system based on learning outcomes from the phased achievements of academic studies}

First of all, we should pay attention to the construction of the evaluation system of students' phased learning outcomes, among which the most important content is the process investigation. That is, in the process of learning, students' attitude and hard work, including in the classroom learning attitude is positive or not, whether do sufficient preparation before class and preparation, after-school review and related practice, whether do homework completion, whether to deep thinking and research of knowledge, whether the relevant case can be analyzed and improved through the knowledge learned, and the problems in real life can be solved or not through the knowledege of learning, whether formed a visible or can examine periodically learning outcomes, the study achievement level evaluation, and so on. The examination and evaluation of this process is not only the effective supervision to the formation of learning results, but also the cornerstone of the construction of curriculum attainment evaluation system. The effective investigation of the learning process is also the premise and guarantee for the formation of effective learning results and the investigation of effective learning results, and it is also the foundation and guarantee indeed for the construction of the curriculum attainment evaluation system.

Secondly, the phase achievement of study is not only the reflection of students' comprehensive ability, but also the reflection of teachers' teaching ability and teaching effect. Based on this, the phase achievement of study also depends on the teachers' teaching ability. That is to say, in order to establish a curriculum development evaluation system from the perspective of academic achievements in the stage, it is necessary to establish the evaluation system of teachers' teaching 
ability, which is including that from the setting of teaching goal to a specific design of classroom teaching, from positioning of teaching focus to construction of teaching plan, etc., every aspects need to establish according to a detailed evaluation terms and evaluation principles, so as to help teachers change their teaching ideas and teaching tactics, make every effort to provide scientific guidance for teachers' teaching activities, standardize the direction of the teaching design, lead teachers to adapt to new environment that take students as the main body of education teaching.

For teachers, for a long time, they have been taking knowledge teaching as their responsibility. The knowledge acceptance of students' is measured by the final exam scores, and the cultivation of students' comprehensive ability is in a careless or insensible situation. In order to change the present situation, teachers should change their teaching methods and ideas with a definite aim through the evaluation of teaching ability, to improve teaching efficiency. For example, classroom design, for traditional teaching methods, teachers only need to impart knowledge accurately. The focus of teaching is knowledge transmission, which is bound to result in emphasis on the explanation of knowledge and neglect of students' understanding and mastery of knowledge. If teachers change their ideas and design classroom teaching centering on students' understanding and comprehension of knowledge, they will pay attention to the interaction with students in the process of knowledge transmission, care about students' understanding and feeling of knowledge, and be able to timely adjust the teaching design and teaching plan, which will have different requirements from classroom to after-class and before class. Such as that the preview before class may change from a simple preview of knowledge to a series of search for relevant knowledge or viewing of relevant images. It guides students to have a grasp of relevant knowledge through a variety of methods and causes students to have some understanding or feeling of knowledge. After class requirements may also be from simple repetition or consolidate into searching activities of knowledge, or the practice of the specific requirements, or finish some small innovation activities, such as that encourage the secretarial major students to provide a professional document for a company according to the knowledge learned, encourage in science and engineering students to make up new programs, or improve some inherent small programs, or create a small machine tools, etc.;
The classroom organization will also be promoted from the teacher's speech to the group inquiry or the teacher and student inquiry learning program. Thus, it can be seen that the evaluation of teachers' teaching ability has a directional guidance and a decisive change in teaching activities. From the teaching design to the specific links of teaching activities, teaching ability evaluation has a decisive influence on teaching effectiveness. Therefore, through the phase achievement of learning outcomes measure curriculum achievement evaluation system, construction of series of teachers' teaching ability evaluation is also the key elements, from the teaching activities of each link to the relevant details, set up the detailed and scientific evaluation system, lay the foundation for construction of the curriculum achievement evaluation system which is based on the learning outcomes.

\subsection{Build curriculum attainment evaluation system based on learning outcomes from the perspective of graduation requirements}

First of all, graduation design is the top priority of graduation requirements. It is the learning achievement that students show on the basis of previous learning experience and learning gains. It is also the last hurdle for students to obtain graduation qualification and even degree certificate. Thus it can be seen that the requirements of graduation design are important indicators for students to complete their studies, and should also become indicators in daily learning. Therefore, the requirements of graduation design can provide exact reference indicators for students to achieve their learning achievements. In other words, graduation design is the embodiment of students' learning achievements, and requirements related to graduation design can also serve as an important item in the construction of curriculum achievement evaluation system which is based on learning achievements.

Secondly, whether teachers' daily teaching activities, or students' daily learning activities, to some extent, are easy to lose focus because of the short class teaching goal or learning goals, but if class goal in the graduation design have to obtain corresponding positioning, either teaching aim or learning goals will get clear orientation, both teachers' teaching activities and the students' daily learning activities will be targeted to continue, and the curriculum attainment will be improved with it.

Thirdly, graduation requirements have certain requirements on students' learning ability, knowledge 
application ability, practical ability and comprehensive quality, which will play a guiding role in guiding daily teaching activities and adjusting teaching direction and teaching focus. Therefore, the degree of achievement of graduation requirements is the guide to curriculum attainment, is the ultimate embodiment of learning results. Therefore, graduation requirements can be an important part in the curriculum attainment evaluation system which is based on learning outcomes.

\subsection{Build curriculum attainment evaluation system based on learning outcomes from the perspective of employability}

Employment, is a problem that every student has to face, but also every knowledge will get the use of. However, employment is not a simple competition of knowledge, but a competition of everyone's comprehensive ability. From the interview to the entry, and even in the future career, we need to communicate with others, need to use our learning ability to absorb new knowledge at any time, and need the support of comprehensive qualities such as quality and perseverance, all of which are the real test and audit of learning results. Therefore, in the construction of the curriculum achievement evaluation system based on learning results, job demands can be connected and evaluation items based on career and employment issues can be added. That is to say, in the daily teaching activities, especially in classroom, teachers and students can close interaction, and through the student's performence such as ability of answer, communication skills, expressive ability, ability to explain problems, thinking ability, and so on, it is will be cosidered to give extra points so that the students will be encouraged to improve comprehensive quality consciously. In addition, in other aspects of teaching activities, such as the homework design, task design, etc., or carried out the actual exercise according to the post demand as a part of final examination, and set up the related addition decentralization items so as to provide the power and platform to students for improve theirs comprehensive quality such as moral quality, perseverance, learning ability, and so on, so as to achieve the purpose of strengthen the students' employment ability. And the right of employability item should be added to the curriculum attainment evaluation system based on learning outcomes, thus, solid foundation for students' future, at the same time, also lay the foundation for establishing a scientific and effective evaluation system.

\section{Matters needing attention in the construction of curriculum attainment evaluation system based on learning outcomes}

First of all, the evaluation system should pay attention to the scientific nature and integrity of each weight distribution. Whether the weight of each element is reasonable or not is directly related to the effectiveness of the evaluation system. If a certain power is too heavy, it will break the balance, causing teachers and students to devote too much energy to a certain aspect, and even go astray; If a certain power is too light, it will be despised, unable to play the positive significance of the weight.

Next, should notice extra points. Such as innovation through knowledge application, or the performance of knowledge transformation, etc., including the published papers, small invention creation, even from a variety of channels and multiple levels show the flexibility of knowledge application, etc., shall be encouraged in different score plus so as to give flexibility characteristic to evaluation system, and prompt the evaluation system development, constantly advance with the times through its tolerance, acceptance and flexibility.

To sum up, curriculum attainment evaluation system based on learning outcomes which is an important guarantee for achieve the effectiveness and achievement of the curriculum centred around the learning outcomes. It is an important measure not only to change single mode of the traditional teaching evaluation, to change the teaching ideas, to change teaching mode, to enhance the effectiveness of teaching, but also important to adapt to the times development which is the only way to improve the teaching quality of education. In reality, it still needs more and more efforts and exploration from many sides to build more and more effective and feasible paths so as to contribute to modern education and teaching.

\section{References}

[1] Zhang JY. Research on the Establishment of higher Education quality assurance System based on student learning outcomes [J]. Think Tank Era, 2019 (34).

[2] Xiong ZH, Xue B. Application of Goal Attainment degree in teaching Quality Evaluation of Physical Chemistry [J]. China Science and Education Innovation Guide, 2014 (10).

[3] $\mathrm{Na} \mathrm{S}$. Analysis of the development status of professional certification in higher engineering education in China and its prospect [J]. Innovation and entrepreneurship education, 2016,7 (1) : 29-34. 
[4] Bin B, Wu WH, Zhang CY, et al. Establishment of the Evaluation System of the Achievement degree of basic Curriculum Teaching -- A Case Study of "Professional English" Course [J]. University Education, 2014 (16).

[5] Zhang JS, Guo RL. Evaluation reform of Curriculum Attainment degree in the Context of Engineering Education Certification [J]. Higher Education Forum, 2016, (6): 72-74.

[6] Gu XW, Wang Q, Qiu JP, et al. Understanding and Reflection on the Degree of "Graduation Requirements" of Engineering Education Certification [J]. Education \& Teaching Forum, 2016, (14) : 24-26.

[7] Gao XS, Tao Z, Min W. Evaluation method and steps of Achievement of Graduation Requirements of Engineering Education Certification [J]. Education \& Teaching Forum, 2016, (51) : 206-208.
[8] Xue JH. Developing Mathematical Thinking and Promoting Effective Learning -- Teaching Segments and Thoughts of "Cognition Corner" [A]. The 18th National New Century Primary School Mathematics Curriculum and Teaching Seminar series and the symposium on "Classroom Teaching guided by Mathematical Literacy -- Spatial Concept" [C].2019.

[9] Xue Y. Quality Assurance lays the foundation for the future -A Review of the International Network of Quality Assurance Institutions in Higher Education [J]. Higher Education Development and Evaluation, 2012 (02).

[10] Zhao BH. Investigation and Research on factors influencing College Students' Learning Outcomes -- Based on data from 35 undergraduate universities [J]. Exploration of Higher Education, 2017 (11). 